\title{
Diet and oral antidiabetic drugs and plasma sugar and insulin levels in patients with maturity-onset diabetes mellitus
}

\author{
J W H DOAR, M E THOMPSON, C E WILDE, P F J SEWELL
}

British Medical fournal, 1976, 1, 498-500

\begin{abstract}
Summary
A longitudinal study was carried out to separate the effects of treatment with diet from those of treatment with glibenclamide and phenformin on the oral glucose tolerance test (OGTT) plasma sugar and insulin levels in 118 patients with maturity-onset diabetes mellitus. Both drugs improved glucose tolerance and random blood sugar levels more than diet alone. The improved glucose tolerance with both drugs was due to a combination of a reduced fasting plasma sugar level and an improved tolerance to the glucose load. Treatment with glibenclamide increased insulin secretion but phenformin had no significant effect. Mean body weight fell slightly during phenformin administration, whereas a small but insignificant rise occurred in patients receiving glibenclamide.
\end{abstract}

\section{Introduction}

The effects of oral antidiabetic drugs have been studied in depth. ${ }^{1}$ Sulphonylureas stimulate pancreatic insulin secretion when administered acutely, inhibit glucose release from the liver, and may potentiate the action of insulin in peripheral tissues. Biguanides seem to increase anaerobic glycolysis and peripheral glucose utilisation and impair gastrointestinal absorption of glucose. The mode of action of both sulphonylureas and biguanides in patients with diabetes mellitus, however, is still disputed. Some workers, for example, have found that sulphonylurea treatment increases plasma insulin levels during an oral glucose tolerance test (OGTT), ${ }^{2}{ }^{3}$ while others have found that it lowers them. ${ }^{4-6}$ In a cross-sectional study Reaven and Miller $^{7}$ found that OGTT plasma insulin levels were higher than normal in patients with untreated mild diabetes mellitus, but as the severity of the diabetes increased the area under the plasma insulin curve became progressively smaller. A longitudinal study of the effects of treatment with diet alone on OGTT plasma glucose and insulin levels has shown a similar trend. ${ }^{8}$ Other studies of the influence of oral antidiabetic drugs on OGTT plasma insulin levels have not always taken the effects of dietary treatment into account. Our study was designed to distinguish the effects of dietary treatment from those of oral antidiabetic drugs on OGTT plasma sugar and insulin levels by a longitudinal control study.

\section{Patients and methods}

One-hundred-and-eighteen patients with newly diagnosed nonketotic diabetes mellitus were investigated before and after two months'

Departments of Medicine and Clinical Chemistry, Doncaster Royal Infirmary, Doncaster DN2 5LT

J W H DOAR, MD, consultant physician

M E THOMPSON, MB, MRCGP, research assistant

C E WILDE, MRCPATH, top grade biochemist

P F J SEWELL, FRCPATH, consultant clinical chemist treatment with diet. The 71 patients with OGTT sugar areas of 1200-2400 units at the second test were randomly allocated to one of three groups. These patients were then treated for four months with diet alone, diet and phenformin, or diet and glibenclamide, after which the third OGTT was carried out. Patients with OGTT sugar areas below 1200 units at the second test continued with diet alone and those with areas above 2400 units received glibenclamide or phenformin in addition to diet. These patients also had a third OGTT four months later and some of those treated with diet alone were included in cross-sectional analyses. In those patients receiving drugs, the dose was adjusted to obtain satisfactory diabetic control in terms of urine tests and random blood sugar levels.

OGTTs were performed using a glucose load of $1 \mathrm{~g} / \mathrm{kg}$ body weight. ${ }^{9}$ Patients were advised to take a diet containing $200 \mathrm{~g}$ of carbohydrate for three days before the first test but remained on their diabetic diet for the second and third tests. Plasma sugar levels were measured by an automated ferricyanide reduction method ${ }^{10}$ and plasma insulin levels in duplicate by a radioimmunoassay technique using charcoal separation. ${ }^{11}$ Insulin assays for each patient's triplet of tests were always carried out in the same run. OGTT plasma sugar and insulin curves were assessed in terms of the total area between each curve and the abscissa, assuming straight lines between individual points. ${ }^{-}$In this centre OGTT sugar areas above 1200 units are considered to indicate diabetes mellitus. Incremental areas were calculated as the area between the curve and a line drawn horizontally through the mean fasting level.

Each patient's degree of obesity was calculated by expressing the body weight as a percentage of the ideal body weight obtained from tables. ${ }^{12}$

Standard statistical methods used included paired and unpaired $t$ tests. Logarithmic conversions were applied when appropriate and all calculations were performed on a Nova 1220 computer.

\section{Results}

Mean OGTT plasma sugar and insulin levels in each of the three treatment groups are shown in the figure, and sugar and insulin areas are shown in table I. During the first two months of diet alone mean glucose tolerance improved in all three groups, and in those who received only a further four months' dietary treatment glucose tolerance remained unchanged. Insulin secretion improved at the second test and this improvement was maintained at the third test. There were significant further improvements in glucose tolerance between the second and third tests with both glibenclamide and

TABLE I-Mean sugar and insulin areas in 24 patients treated with diet alone, 22 treated with phenformin and diet, and 25 treated with glibenclamide and diet at three glucose tolerance tests

\begin{tabular}{|c|c|c|c|c|c|c|c|}
\hline & $\mid \begin{array}{c}\text { Weight } \\
(\mathbf{k g})\end{array}$ & $\begin{array}{c}\% \text { of ideal } \\
\text { body } \\
\text { weight }\end{array}$ & Age & $\begin{array}{c}\text { Sugar } \\
\text { areas } \\
\text { (units) }\end{array}$ & $\begin{array}{l}\text { Sugar } \\
\text { incremental } \\
\text { areas (units) }\end{array}$ & $\begin{array}{c}\text { Insulin } \\
\text { areas } \\
\text { (units) }\end{array}$ & $\begin{array}{l}\text { Insulin } \\
\text { incremental } \\
\text { areas (units) }\end{array}$ \\
\hline \multicolumn{8}{|c|}{ Diet alone group } \\
\hline $\begin{array}{l}\text { OGTT } 1 \\
\text { OGTT } 2 \\
\text { OGTT } 3\end{array}$ & $\begin{array}{l}75 \cdot 5 \\
71 \cdot 4 \\
71 \cdot 1\end{array}$ & $\begin{array}{l}123 \\
116 \\
115\end{array}$ & 53 & $\begin{array}{l}2298 \\
1754 * * * \\
1718\end{array}$ & $\begin{array}{l}809 \\
770 \\
745\end{array}$ & $\begin{array}{l}149 \\
187^{* *} \\
186\end{array}$ & $\begin{array}{l}74 \\
123^{* * *} \\
125\end{array}$ \\
\hline \multicolumn{8}{|c|}{ Phenformin group } \\
\hline $\begin{array}{l}\text { OGTT } 1 \\
\text { OGTT } 2 \\
\text { OGTT } 3\end{array}$ & $\begin{array}{l}75.6 \\
71 \cdot 6 \\
70.0\end{array}$ & $\begin{array}{l}128 \\
121 \\
118\end{array}$ & 57 & $\begin{array}{l}2239 \\
1778 * * * \\
1364 * * *\end{array}$ & $\begin{array}{l}755 \\
688 \\
475 * * *\end{array}$ & $\begin{array}{l}168 \\
200^{*} \\
183\end{array}$ & $\begin{array}{l}90 \\
132 * * * \\
120\end{array}$ \\
\hline \multicolumn{8}{|c|}{ Glibenclumide group } \\
\hline $\begin{array}{l}\text { OGTT } 1 \\
\text { OGTT } 2 \\
\text { OGTT } 3\end{array}$ & $\begin{array}{l}74 \cdot 5 \\
71 \cdot 2 \\
71 \cdot 7\end{array}$ & $\begin{array}{l}122 \\
116 \\
117\end{array}$ & 58 & $\begin{array}{l}2207 \\
1739 * * * \\
1291 * * *\end{array}$ & $\begin{array}{l}760 \\
690^{*} \\
574^{* *}\end{array}$ & $\begin{array}{l}154 \\
174 \\
212 * *\end{array}$ & $\begin{array}{r}94 \\
116 \\
133\end{array}$ \\
\hline
\end{tabular}

Significance of difference between mean value and that of preceding test:
P $<0.05 ; * * \mathrm{P}<0.01 ; * * * \mathrm{P}<0.001$. 


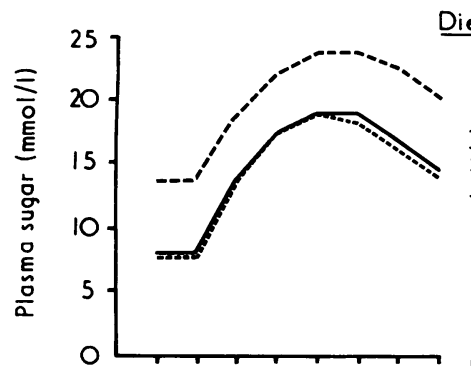

Diet alone
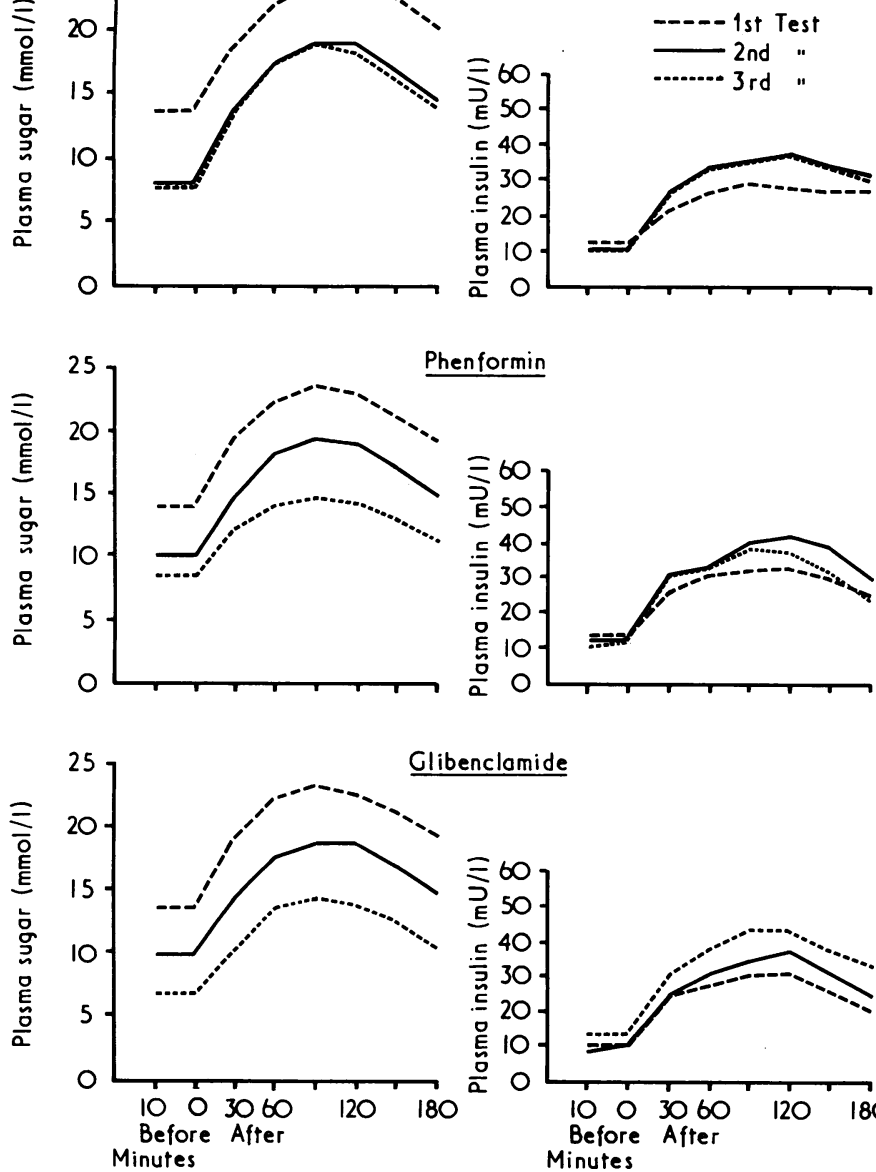

Mean OGTT plasma sugar and insulin levels in 24 patients treated with diet alone, 22 treated with diet and phenformin, and 25 treated with diet and glibenclamide at three glucose tolerance tests.

Conversion: SI to traditional units-Glucose: $1 \mathrm{mmol} / 1 \approx 18 \mathrm{mg} / 100 \mathrm{ml}$.

phenformin, which indicated that these drugs had an effect over and above that of diet alone. The mean insulin area in the glibenclamide group increased by $37.3 \pm(\mathrm{SD}) 66.7$ units $(\mathrm{P}=0.01)$, whereas a small but not significant fall occurred in the phenformin group $(17 \cdot 4 \pm 61 \cdot 1$ units). The mean increase of insulin area in the glibenclamide group was significantly greater than that of the phenformin group $(P<0.01)$ There were no significant changes in the mean fasting plasma insulin levels apart from a small rise in the glibenclamide group between the second and third tests $(3 \cdot 4 \pm 5 \cdot 4 \mathrm{mU} / 1 ; \mathrm{P}<0.01)$.

Mean random blood sugar levels taken in the diabetic clinic five days before each test showed similar trends to the OGTT results (table II) and indicated a satisfactory degree of control in the drug groups before the third test.

While the three groups were well matched for mean OGTT sugar area $(1754,1778$, and 1739 units in the diet, phenformin, and glibenclamide groups respectively), mean degree of obesity $(116,121$, and $116 \%$ ideal body weight), and age (53,57, and 58 years) at the second test, the relations between glucose and insulin levels in the drug groups were difficult to analyse because of the higher mean OGTT sugar area in patients treated with diet alone at the third test. A fourth group was formed that consisted of 24 patients, some of whose sugar areas after the second test were less than 1200 units, and who had continued with diet until they were retested four months

TABLE II-Mean random blood sugar levels (mmolll) before each of three glucose tolerance tests

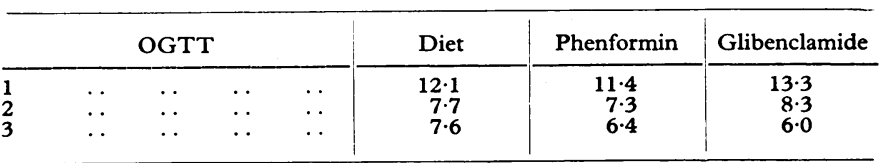

Conversion: SI to traditional units-Glucose $1 \mathrm{mmol} / 1 \approx 18 \mathrm{mg} / 100 \mathrm{ml}$.
TABLE III-Mean OGTT plasma sugar and insulin areas in four groups of patients

\begin{tabular}{l|c|c|c|c|c}
\hline & $\begin{array}{c}\text { No of } \\
\text { patients }\end{array}$ & $\begin{array}{c}\text { Mean } \\
\text { age }\end{array}$ & $\begin{array}{c}\% \text { of mean } \\
\text { ideal } \\
\text { body weight }\end{array}$ & $\begin{array}{c}\text { Mean ( } \pm \text { SD }) \\
\text { OGT } \\
\text { sugar } \\
\text { area (units) }\end{array}$ & $\begin{array}{c}\text { Mean ( } \pm \text { SD) } \\
\text { OGT } \\
\text { insulin area } \\
\text { (units) }\end{array}$ \\
\hline $\begin{array}{l}\text { Diet alone } \\
\text { Phenformin } \ldots\end{array}$ & 24 & 53 & 115 & $1718 \pm 288$ & $186 \pm 129$ \\
Glibenclamide. & 25 & 57 & 118 & $1364 \pm 290$ & $183 \pm 98$ \\
Selected diet alone & 24 & 56 & 117 & $1291 \pm 267$ & $212 \pm 116$ \\
\hline
\end{tabular}

later. This group was satisfactorily matched with the drug-treated groups after the third test (table III). The mean insulin area in this selected group did not differ significantly from that of the glibenclamide or phenformin groups (table III).

Both the glibenclamide and phenformin groups showed a significant reduction in the mean OGTT sugar incremental areas between the second and third tests (table I; $P<0.01$ and $P<0.001$ respectively), which indicated improved tolerance to the glucose load. The mean OGTT sugar incremental area in the phenformin group was smaller than that in the glibenclamide and diet groups. The mean fasting plasma sugar levels at the third test in these three groups, however, varied from 6.61 to $8.99 \mathrm{mmol} / 1$ (119 to $162 \mathrm{mg} / 100 \mathrm{ml}$ ). Since the OGTT sugar incremental area varies with the fasting plasma sugar level, ${ }^{13}$ patients with fasting plasma sugar levels at the third test that matched those of the phenformin group were selected from both the diet and glibenclamide groups; they included some patients whose treatment was not randomly allocated (table IV). The mean OGTT sugar incremental area in the diet alone group was similar to that of the glibenclamide group but significantly greater than that of the phenformin group $(P<0.05)$ (table IV).

TABLE IV-Mean $( \pm S D)$ OGTT sugar incremental areas in three groups of patients matched for fasting plasma sugar levels

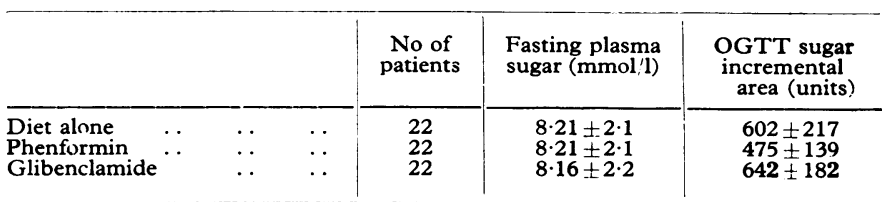

Mean body weight fell significantly in all three groups between the first and second tests $(P<0.001)$. While no further significant weight change occurred between the second and third tests in the diet alone and glibenclamide groups, a further small reduction was observed in the patients receiving phenformin $(1 \cdot 6 \pm 2.9 \mathrm{~kg} ; \mathrm{P}<0.02)$.

\section{Discussion}

The influence of oral antidiabetic drugs on the relation between glucose and insulin levels in patients with diabetes mellitus is difficult to evaluate. Apart from possible differences between drugs, even of the same group, the effect of coincident dietary treatment must be taken into account. A further variable is the length of treatment. Treatment with diet alone affects both glucose tolerance and OGTT plasma insulin levels ${ }^{8}$; while glucose tolerance improved in most patients, those with severe diabetes initially had higher OGTT plasma insulin levels after two months' treatment with diet alone whereas insulin secretion fell in patients with mild diabetes. In the present study the improvement in glucose tolerance was greater with phenformin or glibenclamide than with dietary treatment alone. A similar trend was found with random blood sugar levels. The reduced OGTT sugar area in both drug groups was due to a combination of a lower fasting plasma sugar level and a reduction in the OGTT sugar incremental area, indicating true improvement of tolerance to an oral glucose load.

Insulin secretion improved in all three groups after treatment with diet alone for two months. After a further four months' treatment there was no change in OGTT insulin area in the diet group, a significant rise in the glibenclamide group 
( $\mathbf{P}=0.01$ ), and a small but insignificant fall in the phenformin group. The two drug groups, however, were no longer matched for OGTT sugar area with the diet group at the third test. Since the OGTT insulin area is related to the sugar area, a fourth group of patients also treated with diet alone for six months, was used for comparison. This group had a mean OGTT sugar area similar to those of the two drug-treated groups. The mean OGTT insulin areas of these three groups did not differ significantly (table III). The significance of this cross-sectional analysis, however, was weakened by the large variations in individual insulin areas. The rise in insulin area detected by the more sensitive longitudinal analysis suggests a definite $\beta$-cytotrophic effect of glibenclamide but does not exclude an additional extrapancreatic mechanism.

Sulphonylureas produce a steep rise in plasma insulin levels when given acutely. ${ }^{1}$ There is doubt, however, about whether this effect is important in long-term treatment. Sheldon et al ${ }^{14}$ carried out repeat glucose tolerance tests in diabetic patients treated with acetohexamide. While glucose tolerance improved progressively throughout the study, the area under the OGTT plasma insulin curve initially increased but later declined. Studies by Reaven and Dray ${ }^{5}$ using chlorpropamide and Turtle $^{6}$ using tolazamide showed improved glucose tolerance and reduced insulin secretion during treatment. In patients treated with diet alone for two months we have shown that the change in OGTT insulin area is related to both the initial OGTT sugar area and the change in that area between the two tests. ${ }^{8}$ Possibly the conflicting results of previous workers may have been due to differences in the severity of diabetes in the patients studied and in the improvement of glucose tolerance obtained.

There have been few studies of the effect of biguanides on the relation between glucose and insulin levels. Abramson and $\mathrm{Arky}^{2}$ observed improved glucose tolerance in 11 patients after three weeks' treatment with phenformin. The mean OGTT plasma insulin curve was lower, as in our study, but the change was not statistically significant. The reduced OGTT sugar incremental area found in our phenformin-treated group suggests impaired gastrointestinal absorption of glucose.

Mean body weight fell significantly in all three groups during the first period of treatment with diet alone. The mean changes during the next four months in the diet and glibenclamide groups were not significant, but a further small reduction $(1.6 \pm 2.9 \mathrm{~kg} ; \mathrm{P}<0.02)$ was observed in the phenformin group. The influence of glibenclamide and phenformin treatment on body weight is unlikely to have much biological significance.

At a time when the long-term safety of treatment with oral antidiabetic drugs has been questioned it is important that their mechanism of action should be better understood. Further studies of the long-term effects of treatment with diet alone, glibenclamide, and phenformin are needed.

We thank Hoechst Pharmaceuticals and the Trent Regional Health Authority for financial support.

Requests for reprints should be addressed to JWHD.

\section{References}

${ }^{1}$ Breidahl, H D, et al, Drugs, 1972, 3, 79.

2 Abramson, E, and Arky, R A, Metabolism, 1967, 16, 204

${ }^{3}$ Feldman, J M, and Lebowitz, H E, Diabetes, 1971, 20, 745.

${ }^{4}$ Duckworth, W C, et al, fournal of Clinical Endocrinology, 1972, 35, 585.

${ }^{5}$ Reaven, G, and Dray, J, Diabetes. 1967, 16, 487.

6 Turtle, J R, British Medical fournal, 1970, 3, 606.

${ }^{7}$ Reaven, G, and Miller, R, Diabetes, 1968, 17, 560.

${ }^{8}$ Doar, J W H, et al, Lancet, 1975, 1, 1263.

9 Wynn, V, and Doar, J W H, Lancet, 1966, 2, 715.

10 Technicon method N-2b.

11 Albano, J D M, et al, Acta Endocrinolugica, 1972, 70, 487.

12 Documenta Geigy, Statistical Tables. Macclesfield, Geigy Pharmaceuticals, 1956.

13 Doar, J W $\mathrm{H}$, unpublished observations.

14 Sheldon, J, Taylor, K W, and Anderson, J, Metabolism, 1966, 15, 874.

\section{SHORT REPORTS}

\section{Removal of impacted rectal foreign body with obstetric forceps}

The removal of an impacted rectal foreign body using obstetric forceps is described. The technique is valuable in accident and emergency departments when other attempts at removal have failed.

\section{Case report}

A 52-year-old man presented at the accident department complaining of rectal pain and inability to open his bowels. Six hours previously he had inserted the polyethylene screw-on waste trap from the U-bend of a sink waste pipe into his rectum. On examination, the hollow cup was firmly impacted in the rectum, open end facing outwards. Under general anaesthesia, the open edge of the cup was felt hard against the ischial tuberosities and could not be drawn down past this obstruction. Short obstetric forceps were then applied, using a technique exactly similar to that in delivering an infant's head, and the cup slowly delivered (see figure). Sigmoidoscopy showed no sign of a rectal mucosal tear and the patient was discharged from hospital the next day.

\section{Discussion}

The large impacted rectal foreign body may tax the accident surgeon's ingenuity in attempting its removal. Various manipulations have been described, including plaster of Paris in glass tumblers and corkscrews for woody objects. ${ }^{1}$ The slightly flexible nature of the cup in this case allowed it to slide into the rectum but the open end then jammed against the bony pelvis. Slow dilatation of the rectum allowed the application of well-lubricated obstetric forceps, which proved to be the only instrument that would encompass the cup without damaging the rectal mucosa. Removal was then simple.

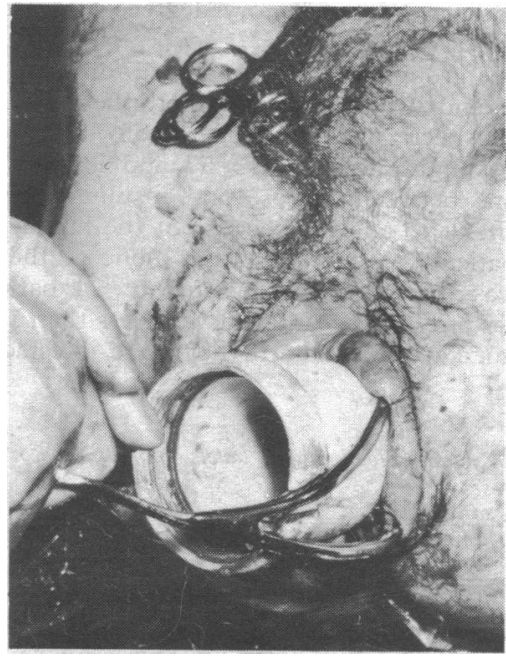

Removal of cup using obstetric forceps. 